\title{
Parvovirus B19-Associated Reactive Arthritis Presented with Erythema Nodosum
}

\author{
Emre ADIGÜZEL1', Koray AYDEMIR'1, Kutay TEZEL'1 , Selvinaz KIZILIRMAK'1, Mehmet Ali TAŞKAYNATAN'1, Ahmet ÖZGÜL² \\ ${ }^{1}$ Department of Physical Medicine and Rehabilitation, Gülhane Military Medical Academy, Turkish Armed Forces Rehabilitation Center, Ankara, Turkey \\ ${ }^{2}$ Clinic of Physical Medicine and Rehabilitation, Akay Hospital, Ankara, Turkey
}

\begin{abstract}
Reactive arthritis (ReA) is a rheumatologic disease characterized by non-purulent arthritis, which occurs 1-4 weeks after gastrointestinal or genitourinary infections. Although mostly caused by bacteria, there are a growing number of viruses that include parvovirus, hepatitis virus, and HIV. Here we report a case of ReA with erythema nodosum that was triggered by parvovirus B19.

Keywords: Reactive arthritis, human parvovirus B19, erythema nodosum
\end{abstract}

\section{Introduction}

Reactive arthritis ( $\operatorname{ReA})$, classified as a member of the spondyloarthritis family, is a rheumatologic disease characterized by non-purulent arthritis, which occurs 1-4 weeks after gastrointestinal or genitourinary infections. There are no diagnostic criteria validated by case-controlled prospective studies or universally accepted by scientific communities. An expanding list of pathogens exists, including bacteria, virus, protozoa, etc. Although mostly caused by bacteria, there are a growing number of viruses, which include parvovirus, hepatitis virus, and HIV. Viral arthritis with HIV has also been reported previously (1). Parvovirus B19-associated ReA is an uncommon disease entity. Parvovirus B19 mostly causes anemia, erythema infectiosum (fifth disease), and hydrops fetalis in pregnant women. It is also known to cause acute and chronic arthralgia/arthritis.

Here we report a case of $\operatorname{ReA}$ with erythema nodosum that was triggered by parvovirus B19. The aim of this report is to bring clinicians' attention to parvovirus-associated ReA.

\section{Case Report}

A 40-year-old woman was admitted in April 2011 with a skin lesion at the lateral side of her left ankle and distal anterior side of her right thigh and with a 2 weeks history of bilateral knee and left ankle joint pain. The patient's complaints first appeared with sore throat 1 month ago. She was diagnosed with acute tonsillitis and used ampicillin $1 \mathrm{~g}$ twice daily for one week. During the antibiotherapy, she noticed a skin lesion at the lateral side of her left ankle and distal anterior right thigh, and after that, joint pain on her bilateral ankle and knee began. Because of her joint pain, non-steroidal anti-inflammatory drugs were prescribed by an orthopedist, but she refused to use these drugs. She had no history of recent urinary tract infection, acute gastroenteritis, uveitis, or sexually transmitted diseases. On admission, her body temperature was $37.3^{\circ} \mathrm{C}$; her pulse rate and blood pressure were normal. There was swelling, tenderness, and heat on her left ankle along with erythematous skin lesions on the lateral side (Figure 1) and distal anterior right 


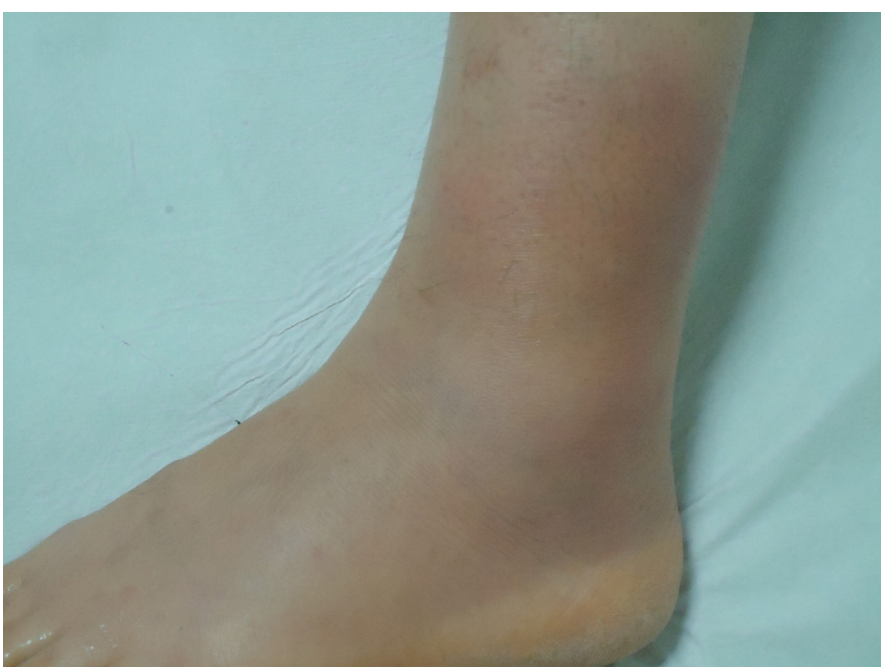

Figure 1. Erythematous skin lesions at the lateral side of the left ankle

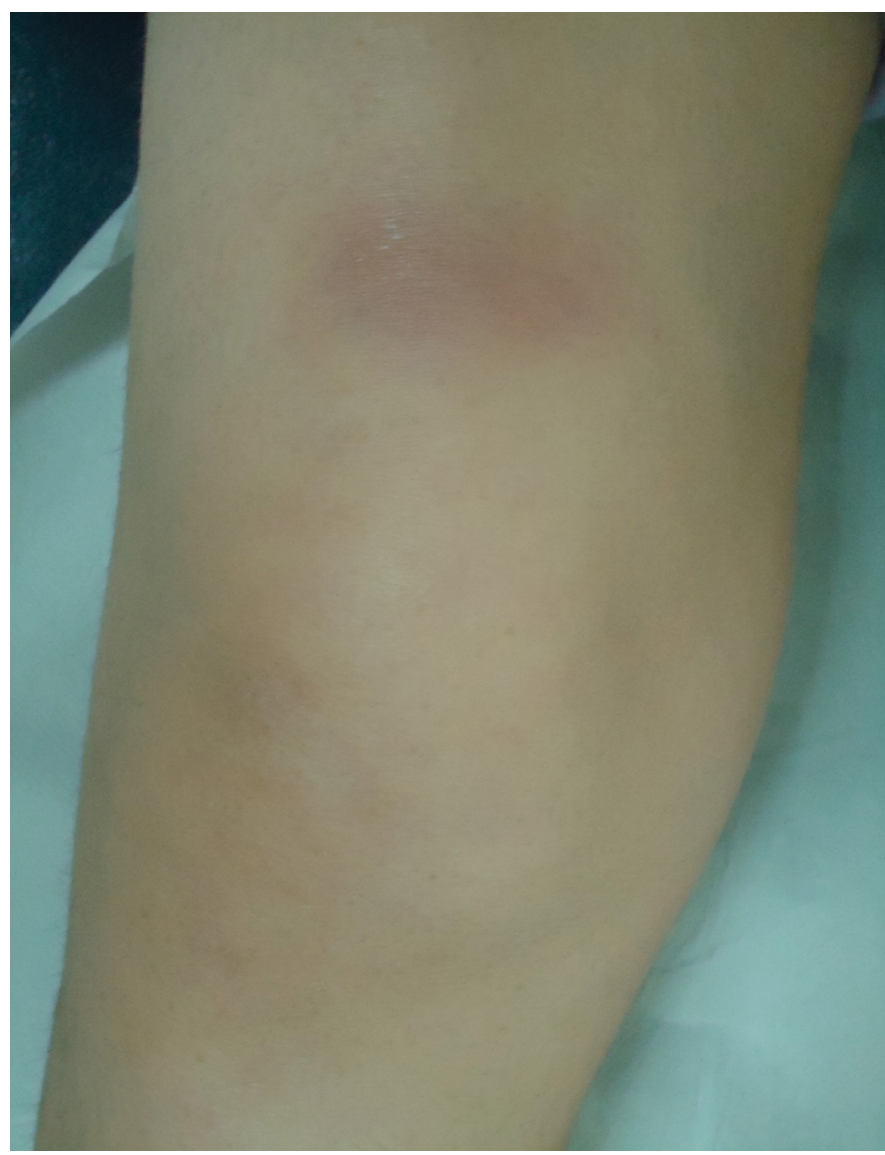

Figure 2. Erythematous skin lesions at the distal anterior right thigh thigh (Figure 2). Ultrasonography of the joints revealed effusion in the bilateral wrists (Figure 3,4), knees, and tibio-talar joints. Direct radiographic examination of the ankle, knee, sacroiliac (SI) joint, and chest were normal. Laboratory studies a showed hemoglobin level of $10.3 \mathrm{~g} / \mathrm{dL}$, a WBC count $7700 / \mu \mathrm{L}$ (neutro-
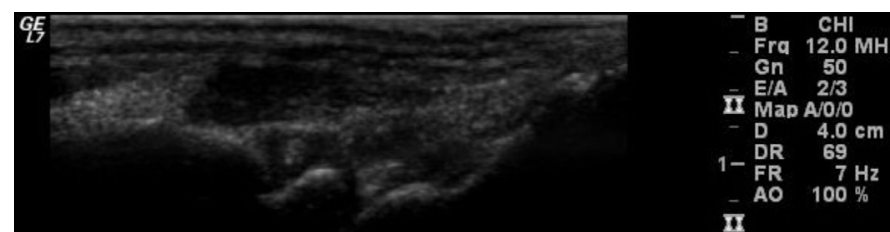

I rc

II

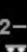

II

3-

4-

Figure 3. Ultrasound evaluation of the left radiocarpal joint and longitudinal scan of the patient showing effusion of the joint

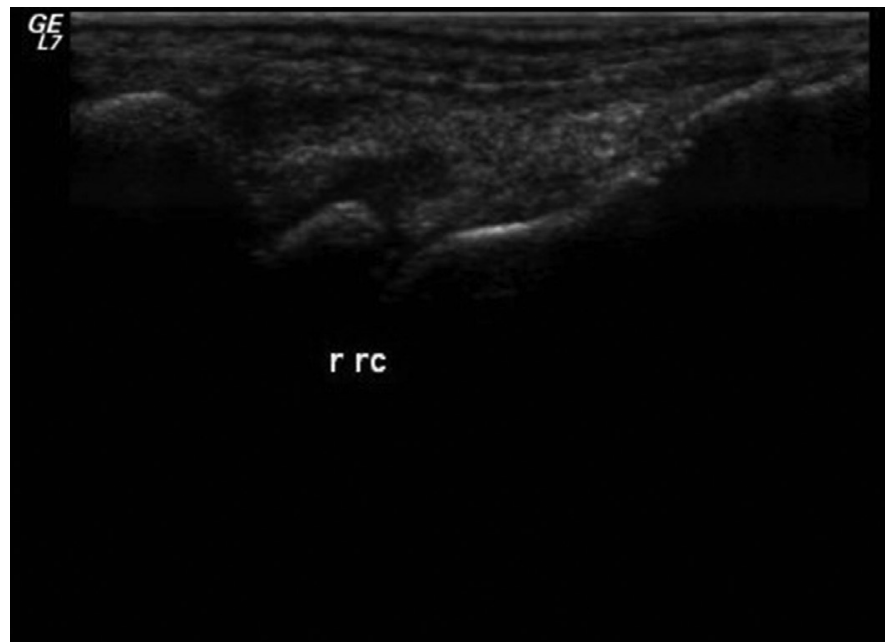

Figure 4. Ultrasound evaluation of the right radiocarpal joint and longitudinal scan of the patient showing effusion of the joint

phils $72.5 \%$, lymphocytes $19.1 \%$, monocytes $7.2 \%$, eosinophils $1.0 \%$, basophils $0.2 \%$ ), a platelet count of $363000 / \mathrm{microL}$, an erythrocyte sedimentation rate of $78 \mathrm{~mm} / \mathrm{h}$, a C-reactive protein level of $1.28 \mathrm{mg} / \mathrm{dL}$ (normal range $0-6 \mathrm{mg} / \mathrm{dL}$ ). ASO, RF and anti-CCP tests were normal. Liver and renal function tests and urinalysis showed no abnormality. While the anti CMV IgM test, Brucella agglutination test, ANA test, and anti-dsDNA tests were negative, the parvovirus B19 lgM test was positive. We diagnosed the patient as having ReA due to parvovirus B19 and prescribed acemetacin $60 \mathrm{mg}$ twice daily and asked her to visit us for a follow-up examination. After two weeks, she reported a significant reduction in joint pain at the follow-up. There was no new skin lesion, and the redness of the lesions disappeared: meanwhile, joint effusions detected by ultrasonography were significantly reduced. Although the C-reactive protein level increased, it was still within the normal range $(3.3 \mathrm{mg} / \mathrm{dL})$. 


\section{Discussion}

The term ReA refers to spondyloarthritis that occurs after an infection by a certain causative agent. Generally, enteric and urogenital pathogens, Chlamydia trachomatis, Yersinia, Salmonella, Shigella, and Campylobacter are known to be associated with $\operatorname{ReA}(2)$. While the clinical symptoms of these agents are mainly diarrhea or urethritis, the inductive infection may be asymptomatic (3). Although the pathogens of bacteria constitute the main inducer, viral arthritis is a commonly overlooked form of ReA. Virus-associated ReA is pronounced for HIV, mostly in the sub-Saharan region (1).

Parvovirus B19 is known to infect humans. Infected individual's age and hematologic and immunologic status may vary as it could be benign to life-threatening. While $25 \%$ of infected patients do not have any signs or symptoms, approximately $50 \%$ of infected patients have flu-like symptoms, muscle pain, and fever. The remaining $25 \%$ of the patients have classical symptoms including rash, arthralgia, and edema $(4,5)$. Along with fifth disease, it may cause joint symptoms or arthritis in both children and adults, mostly women. While it shows polyarticular symmetric involvement in adults, the pattern in children has been reported to be asymmetric distal involvement. However, our patient was an adult and had symmetric polyarthritis affecting both upper and lower extremities. Due to the sonographic detection of the arthritis, it should be remembered that the patient had no complaints regarding the hand and wrists.

The diagnosis of $\operatorname{ReA}$ is challenging. For the diagnosis, obtaining the causative organism or a sign of recent infection directly is mandatory. As ReA mainly occurs after a period, the direct infection may disappear through resolution. In that case, the detection of parvovirus B19 IgM, which may remain elevated for 2-3 months, is helpful. Parvovirus B19 lgG can be detectable long time and shows an infection at any time. Other findings regarding inflammation, ESR-CRP-CBC, etc. are nonspecific but helpful.

Regarding problems in the diagnosis of infectious arthropathies, Tuuminen et al. (6) reported that acute parvovirus B19 infections could cause non-specific serologic positivity such as Borrelia, Salmonella, and Campylobacter infection and presented two different cases with polyclonal antibody production. Our patient had no gastroenteritis or Lyme disease, so we excluded these diagnoses. However, such an interrelation should be kept in mind.

Parvovirus B19-associated joint symptoms occur in approximately $8 \%$ of children and $80 \%$ of adults $(4,7,8)$. Therefore, it should be frequently diagnosed. Joint involvement is more common in adult females than adult males or children $(4,9)$. Affected joints are commonly painful and swollen. This viral agent may affect any joint; it commonly symmetrically represents in the wrist, hand, knee, and ankle. Generally, joint symptoms usually resolve in three weeks, but in some cases, they may remain for months. Parvovirus B19-associated arthritis does not cause joint destruction (10).

The joint disease pathogenesis is not clear for parvovirus B19. There are some suggestions regarding arthritis; one of them is that people with certain haplotypes, HLADR4 or B27 in particular, are the most susceptible ones for related arthritis $(11,12)$. Immediately after a serum B19-specific antibody response comes to a measurable level, joint symptoms occur. Although it was reported that parvovirus B19 DNA was detected in the joint fluid specimens of some patients with acute parvovirus B19 arthritis, it is unclear yet whether viral DNA isolation from the joint space indicates direct infection or if it is due to systemic virus seeding.

Parvovirus B19 is also known for its cutaneous manifestations. Erythema infectiosum is the classical presentation. In addition, petechial and purpuric rashes, papular eruptions, and rarely erythema nodosum, erythema multiforme, and livedo reticularis may be seen. Approximately $75 \%$ of patients will develop a rash, but less than $20 \%$ of them will present with the typical slapped cheeks rash. In the absence of rash, parvovirus infection may be mistaken for acute rheumatoid arthritis.

Erythema nodosum can accompany arthritis in patients with sarcoidosis (13), histoplasmosis (14), coccidiomycosis (15), yersiniosis (16), and Chlamydia pneumonia (17). Sarcoid arthropathy commonly symmetrically involves ankles and is followed by other large joints of the lower extremity (18). The arthritis of our patient resembled sarcoidosis, but there was no sign such as hilar adenopathy or pulmonary infiltration on the chest X-ray that could support this diagnosis. Due to absence of any positive history or sign for other fungal agents, yersiniosis, or Chlamydia pneumoniae infection, we did not perform further diagnostic tests.

\section{Conclusion}

In the present case, the patient showed both erythema nodosum and joint symptoms. The cutaneous lesions and previous sore throat should alert the clinician for parvovirus B19 ReA. Because of the asymptomatic cases, parvovirus B19-associated ReA may be under-diagnosed. When the physicians suspect ReA, parvovirus B19 tests should be conducted together with conventional laboratory investigations.

Informed Consent: Written informed consent was obtained from patient who participated in this case.

Peer-review: Externally peer-reviewed.

Author Contributions: Concept - A.Ö., E.A.; Design - E.A., K.T.; Supervision - M.A.T., A.Ö., K.A.; Resource - E.A., S.K.; Materials - E.A., A.Ö.; Data Collection and/or Processing - E.A., K.T.; Analysis and/or Interpretation - M.A.T., A.Ö.; Literature Review - E.A., A.Ö.; Writer - E.A., A.Ö.; Critical Review - K.A., M.A.T., A.Ö.

Conflict of Interest: No conflict of interest was declared by the authors

Financial Disclosure: The authors declared that this study has received no financial support.

\section{References}

1. Cuellar ML, Espinoza LR. Rheumatic manifestations of HIV-AIDS. Baillieres Best Pract Res Clin Rheumatol 2000;14:579-93. [CrossRef]

2. Braun J, Kingsley G, van der Heijde D, Sieper J. On the difficulties of establishing a consensus on the definition of and diagnostic investigations for reactive arthritis. Results and discussion of a questionnaire prepared for the 4 th International Workshop on Reactive Arthritis, Germany, July 3-6, 1999. J Rheumatol 2000;27:2185-92.

3. Carter JD, Hudson AP. Reactive arthritis: clinical aspects and medical management. Rheum Dis Clin North Am 2009;35:21-44. [CrossRef] 
4. Woolf AD, Campion GV, Chiswick A, Wise S, Cohen BJ, Klouda PT, et al. Clinical manifestations of human parvovirus B19 in adults. Arch Intern Med 1989;149:1153-6. [CrossRef]

5. Hayakawa H, Tara M, Niina K, Osame M. A clinical study of adult human parvovirus B19 infection. Intern Med 2002;41:295-9. [CrossRef]

6. Tuuminen $T$, Hedman K, Söderlund-Venermo M, Seppälä I. Acute parvovirus B19 infection causes nonspecificity frequently in Borrelia and less often in Salmonella and Campylobacter serology, posing a problem in diagnosis of infectious arthropathy. Clin Vaccine Immunol 2011;18:167-72. [CrossRef]

7. Ager A, Chin TD, Poland JD. Epidemic erythema infectiosum. N Engl J Med 1966;275:1326-31. [CrossRef]

8. Joseph PR. Fifth disease: the frequency of joint involvement in adults. N Y State J Med 1986;86:560-3.

9. Scroggie DA, Carpenter MT, Cooper RI, Higgs JB. Parvovirus arthropathy outbreak in southwestern United States. J Rheumatol 2000;27:2444-8. .

10. Speyer I, Breedveld FC, Dijkmans BA. Human parvovirus B19 infection is not followed by inflammatory joint disease during long term follow-up. A retrospective study of 54 patients. Clin Exp Rheumatol 1998; 16:576-8.
11. Klouda PT, Corbin SA, Bradley BA, Cohen BJ, Woolf AD. HLA and acute arthritis following human parvovirus infection. Tissue Antigens 1986;28:318-9. [CrossRef]

12. Jawad AS. Persistent arthritis after human parvovirus infection. Lancet 1993;341:494. [CrossRef]

13. Gran JT, Bohmer E. Acute sarcoid arthritis: a favourable outcome? A retrospective survey of 49 patients with review of the literature. Scand J Rheumatol 1996;25:70-3. [CrossRef]

14. Thornberry DK, Wheat LJ, Brandt KD, Rosenthal J. Histoplasmosis presenting with joint pain and hilar adenopathy. "Pseudosarcoidosis". Arthritis Rheum 1982;25:1396-402. [CrossRef]

15. Einstein HE. Bilateral hilar adenopathy. Ann Intern Med 1973;78:787. [CrossRef]

16. Luqmani RA, Dawes PT. Yersinia arthritis with erythema nodosum. Postgrad Med J 1986;62:405. [CrossRef]

17. Marie I, Lecomte F, Levesque $H$, Janvresse $C$, Kerleau JM, Cailleux N, et al. Löfgren's syndrome as the first manifestation of acute infection due to Chlamydia pneumoniae: a prospective study. Clin Infect Dis 1999;28:691-2. [CrossRef]

18. Visser H, Vos K, Zanelli E, Schreuder GM, Speyer I, Breedveld FC, et al. Sarcoid arthritis: clinical characteristics, diagnostic aspects, and risk factors. Ann Rheum Dis 2002;61:499-504. [CrossRef] 